\title{
DEUTSCHES FEST: VERGONHA E ORGULHO EM UM EVENTO DE MOBILIZAÇÕES SIMBÓLICAS E ECONÔMICAS
}

\author{
DEUTSCHES FEST: SHAME AND PRIDE IN A SITUATION OF SYMBOLIC AND \\ ECONOMIC MOBILIZATIONS
}

\author{
Neiva Maria Jung ${ }^{*}$ \\ Regina Coeli Machado e Silva**
}

\begin{abstract}
RESUMO
Neste artigo temos como objetivo examinar práticas de linguagem que circunscrevem fenômenos de mercantilização de linguagem em um evento festivo - Deutsches Fest -que acontece anualmente em uma cidade do Oeste do Paraná. Argumentamos que houve em parte um movimento inverso ao sugerido por Heller e Duchêne $(2012,2016)$ : de uso inicial da linguagem como recurso ou valor agregado na festa (lucro) resultou em seu uso como marca identitária (orgulho). Alguns moradores que se envergonhavam de serem "colonos alemães" passaram, com a festa, a se orgulharem de práticas que assim os identificam. Realizada anualmente a partir de 2012, a festa atualiza a história dos moradores, descendentes de imigrantes alemães vindos do Rio Grande do Sul na década de 1960, e as identidades local/regional e nacional ("alemães" versus cidadãos brasileiros), mostrando como esse evento possibilitou essa mudança identitária. Nosso foco são as práticas de linguagem escrita e oral - anúncios em jornais, comerciais da mídia, entrevistas, postagens no Facebook, programas de tevê -, e práticas semióticas - as cores da bandeira alemã e o vestuário - na realização da festa, um evento público e coletivo com duração de três dias. Os resultados sugerem que essas práticas são mobilizações simbólicas e econômicas da linguagem que tanto impulsionam o evento turístico comercial quanto promovem discursos de orgulho pelo pertencimento a uma "cultura alemã local".
\end{abstract}

Palavras-chave: mercantilização da linguagem; comunidade de imigração; festa.

\section{ABSTRACT}

In this article, we aim to approach language practices that circumscribe language commodification phenomena in a festive event - Deutsches Fest -, which takes place annually in a small town in the Brazilian state of Paraná. We argue that there has been a movement opposite to that suggested by Heller and Duchêne $(2012,2016)$ : from the use of language at the festival initially as a resource or aded commercial value (profit) has resulted in its use as an identity mark (pride). Some residents who used to be ashamed of being "colonos" (settlers), have become, through the festival, proud of the practices that identity them as such. Held annually since 2002, the festival rewrites the history of the residents' migration, as these descendants of German immigrants who left the state Rio Grande do Sul in the 1960s revise local/regional and national identities ("Germans" versus Brazilian citizens). Our focus is on written and oral language practices - which circulate in newspapers, media commercials, interviews, Facebook posts, TV programs -, and semiotic practices such as the colors of the German flag and clothing, as well as the Festival itself, a 3-day public and collective event celebrated through dance, dinners, barbecues, draft beer, sports competitions and other recreational activities. The results demonstrate that these practices are symbolic and economic mobilizations of language marked by tensions that have raised discourses of pride of belonging to a "local German culture" shared by the residents.

Keywords: commodification of language; migration community; festival.

\section{INTRODUÇÃO}

Este artigo ${ }^{2}$ está inserido em um debate sobre o papel central da linguagem em suas articulações com o capitalismo tardio. Nesse debate, os recursos linguísticos comunicativos e simbólicos passaram a figurar em trocas econômicas, fenômeno que Heller $(2003,2010)$ e Heller e Duchêne $(2012,2016)$ identificaram como "mercantilização da linguagem". Houve, segundo os autores, alterações cruciais de usos de linguagem como marca cultural, de identidade (orgulho), para linguagem também como recurso ou valor comercial agregado (lucro).

Em diálogo com essa discussão, propomos para este artigo examinar como práticas da linguagem em uma festa - a Deutsches Fest promovida em um Município do Oeste do Paraná - assumem múltiplas significações

\footnotetext{
* Universidade Estadual de Maringá (UEM), Maringá, PR, Brasil. neiva.jung@gmail.com Orcid: https://orcid.org/0000-0002-7249-7816

** Universidade Estadual do Oeste do Paraná (Unioeste), Campus de Foz do Iguaçu, PR, Brasil. Pesquisador Produtividade Cnpq. coeli.machado@yahoo.com.br

Orcid: https://orcid.org/0000-0002-0874-8086

1. Os nomes de referências locais e de participantes foram substituídos por pseudônimos. O local será apresentado como o Município/a Cidade.

2. Agradecemos a Pedro M. Garcez e aos pareceristas pela leitura atenta, observações e sugestões sobre o texto. Todas as imperfeições remanescentes são de nossa inteira responsabilidade.
} 
com atualizações ambíguas e, por vezes contraditórias, que incluem: a história da imigração ("colonização" versus ocupação pelo sistema de posses), as identidades locais/regionais (alemães) versus identidade nacional (brasileiros), e a promoção da festa como objeto turístico à venda suscitando orgulho da identidade local, invertendo o sentimento de vergonha da identidade de "colono". Heller (2011, p. 27) destaca a existência de um "mercado de performances e bens culturais" ${ }^{\prime \prime}$, no qual "a linguagem desempenha um papel importante no processo de autenticação". Queremos mostrar quais particularidades culturais vendem, como são anunciadas em práticas de linguagem e o que significam nesse mercado turístico do oeste paranaense. Trata-se, como afirmam Heller e Duchêne (2016, p. 144), de observar situadamente o surgimento de fenômenos de mercantilização da linguagem e seus contornos complexos, para melhor explicá-los e compreender suas consequências sobre como imaginamos objetos tradicionais como variabilidade linguística, comunidade e identidade, e a relação desses conceitos com a ideia de nação.

Nosso argumento é que ocorreu uma reversão da vergonha de ser "colono alemão" para orgulho dessa identidade, um caminho certamente favorecido pelo contexto mais abrangente de valorização da linguagem no capitalismo global. Onde não havia orgulho local da herança de "colono", de mercantilização e globalização propiciaram a (re)invenção de uma procedência germânica difusa, associada à Alemanha, e vista como prestigiosa. As práticas de linguagem aí existentes se transformaram em recursos para a busca de autenticidade identitária. A Deutsches Fest as recompõe e as revive, articulando-as a interesses comerciais para criação de um mercado turístico local, cujo efeito visível e inesperado é a afirmação do crescente orgulho de ser do local, identificação indissociável de pertencer à "cultura germânica". Tal identificação na festa alterou preconceitos linguísticos - relacionados, especialmente, à fala do português local, reconhecido localmente como brasileiro ${ }^{5}$, e vivenciados por falantes e não falantes de alemão ${ }^{6}$ - distanciando-os do sentimento de serem "colonos envergonhados" (JUNG, 2009). Além de atrativo turístico, a Deutsches Fest é uma festividade pública, criada e organizada por alguns moradores da cidade sob a égide do poder municipal, e coletiva porque celebra o pertencimento a um grupo identitário (descendentes de imigrantes alemães, contrastados com a nacionalidade brasileira), espacial (moradores locais contrastados com moradores da área colonizada pelo sistema de posses assim como com os do município vizinho) e temporal (a história do grupo cristalizada em diversos símbolos).

Os dados utilizados para este artigo são resultantes de entrevista concedida por duas pessoas envolvidas com a organização da festa em diferentes edições. Analisamos também notícias publicadas em jornais locais, propagandas comerciais em postagens no Facebook e programas de televisão, além de fotografias da cidade e da festa de mais de uma edição da festa. Incorporamos, não explicitamente, nossa autorreflexividade como autoras, posicionadas. A primeira é linguista aplicada e pesquisadora sobre multilinguismo em comunidades de imigração no sul do Brasil; a segunda é antropóloga e pesquisadora na região de fronteira entre Brasil, Paraguai e Argentina (2013, 2020). Nesse sentido, abordamos a linguagem da festa na área da Linguística Aplicada, um campo situado em "cruzamentos de fronteiras, do que é difuso ${ }^{7}, "$ segundo Heller (OLIVEN; GARCEZ, 2020, p. 326).

Para desenvolver nosso argumento, apresentamos, na próxima seção, uma discussão sobre mercantilização da linguagem no capitalismo recente; na seção dois, descrevemos o contexto de pesquisa; na seção três, o evento festivo cuja particularidade é, desde o seu título, Deutsches Fest, expressivo da associação feita pelo senso comum entre língua e cultura, comumente presente em grupos descendentes de imigrantes de origem alemã no Brasil ${ }^{8}$; na seção quatro, apresentamos uma análise das práticas de linguagem da festa e, finalmente, uma seção com algumas considerações finais.

3. A tradução das citações foi feita por nós para fins deste artigo.

4. "Colono" é uma categoria comum no Sul do Brasil para se referir, caricaturalmente, aos moradores da área rural, análogo ao estereótipo do caipira brasileiro, assim designado pela história dos núcleos coloniais instituídos pelas políticas de imigração do final do século XIX

5. Com relação à nomeação das línguas, grafamos todas com letra minúscula, flexionando-as de acordo com o sistema da língua portuguesa, como sugeriram Fiorin e Petter (2008, p. 10), isto é, nomear com igualdade as línguas.

6. Trata-se da variedade amplamente reconhecida na literatura como hunsrückisch, mas que localmente é identificada como alemão (por exemplo: fulano fala "alemão"). Sem desconsiderar as controvérsias a respeito da língua falada por esses migrantes, como "dialeto hunsrückisch" ou "Língua Brasileira de Imigração", como apresentado pelo Inventário do hunsrückisch (ALTENHOFEN, MORELLO, 2018), utilizaremos alemão porque é o modo como os participantes se referem à língua.

7. De acordo com Heller (2020), "é Antropologia Linguística em um certo canto da Antropologia na América do Norte, é Sociolinguística em boa parte do resto do mundo, é Linguística Aplicada no Brasil e na Grã-Bretanha, talvez em outros lugares também" (OLIVEN, GARCEZ, 2020, p. 326).

8. A associação entre língua e cultura é comum desde a formação dos Estados-nação modernos pela afirmação de "uma língua, um povo, um território". Essa associação aparece de modo claro nas pesquisas de Seyferth (1997) sobre o tema da relação Estado nacional e imigração alemã no Sul do país, principalmente durante o período do Estado Novo. 


\section{MERCANTILIZAÇÃO DA LINGUAGEM: RECURSOS COMUNICATIVOS E SIMBÓLICOS}

No momento histórico do capitalismo tardio, o regime de regulação global dos mercados e as tensões daí emergentes dão origem, segundo Heller e Duchêne (2012, p. 3), "[..] a novos tropos discursivos nos quais a linguagem desempenha um papel particularmente central, não apenas por seu papel na regulação e na legitimação de espaços político-econômicos, mas também pelo surgimento do setor terciário como um elemento definidor da nova economia globalizada". Se, na modernidade, associada ao orgulho, ajudou a construir a identificação característica do Estado-nação moderno, recentemente a linguagem passou a marcar distinção para inserção no mercado de trabalho global por meio de ideologias que a apresentam como habilidade técnica, ou feixe de habilidades, e meio de atribuir valor a produtos culturais como se fossem "autênticos". Trata-se da mercantilização da linguagem (HELLER, 2010).

Nesse enquadramento, a linguagem é compreendida tanto como recurso linguístico e simbólico articulado a essa nova economia global quanto produtora de distinção social (BOURDIEU, 2017). Entendida como prática, a linguagem é parte de um conjunto complexo de atividades sociais e econômicas, nas quais atores sociais utilizam recursos linguísticos para agenciar outros recursos, algumas vezes mínimos, e alcançar propósitos específicos em condições específicas. Como discutem Heller e McElhinny $(2017$, p. 3), as pessoas têm interesse na linguagem porque ela tem valor e "[...] tem valor porque está articulada ao modo como todos os tipos de recursos são produzidos, como circulam e como são consumidos, incluindo também como eles são identificados como recursos". Não se trata, de acordo com Heller (2010), de uma ruptura com ideologias de linguagem como um sistema delimitado, associada a um Estado-nação, uma comunidade imaginada (ANDERSON, 2008) ou a um grupo social unificado, uma identidade, mas de uma apropriação, e da extensão dessa ideologia sob novas condições.

Na modernidade, a ideologia de linguagem que associa língua ao Estado-nação foi uma estruturação vinculada à formação dos Estados nacionais. A terminologia de Estado, nação e língua em seu significado moderno não era utilizada pelo menos até 1884, quando pela primeira vez foi registrada no Dicionário da Real Academia Espanhola, como escreveu Hobsbawm (1990, p. 27). "Aí, pela primeira vez, aprendemos que a língua nacional é a língua oficial e literária de um país e, à diferença de dialetos e línguas de outras nações, é a língua geralmente falada". Do ponto de vista sócio-histórico, os interesses comuns das classes burguesa e popular contra privilégios particulares da aristocracia atuaram como forças para a construção da nação, contudo, não foram articulados à nação moderna de modo igual. Na Alemanha, a língua popular falada se tornou um elemento central, na França revolucionária, era secundária, uma vez que a ideia de nação pertencia a um país disposto a adotar as leis, as liberdades e as características comuns do povo livre9. De qualquer modo, a língua foi um elemento fundamental na formação das nações modernas pela instituição de línguas oficiais (BOURDIEU, 1982) e, correlativamente, da educação (ANDERSON, 2008; BOURDIEU, 2007; GELLNER, 1993), vias para unificação simbólica dos Estados nacionais.

No capitalismo tardio, o argumento de Heller e colaboradores é de que estaríamos dando passos na direção do pós-nacionalismo (HELLER, 2011), visto que recursos linguísticos instrumentais e simbólicos figuram em trocas econômicas. Grandes crises econômicas teriam levado a uma reconfiguração dos mercados econômicos devido a cinco processos interconectados: saturação de mercados, expansão, distinção (ou valor agregado), terciarização e flexibilização, com o objetivo central de expandi-los. A linguagem passa a ter um papel importante nessa reconfiguração ao:

[...] (a) gerenciar o fluxo de recursos ao longo das relações compactadas de espaço e relações espaço-tempo, (b) fornecer valor agregado simbólico aos recursos produzidos industrialmente, (c) facilitar a construção e o acesso a nichos de mercado, e (d) desenvolver conhecimentos mediados linguisticamente e indústrias de serviços. (HELLER, 2010, p. 103).

São, conforme Heler e McElhinny (2017, p. 7), ideologias da linguagem articuladas com relações de poder ou com ideias associadas a certos grupos. Essas ideologias da linguagem estão presentes em três mudanças de discurso: discursos de direitos cada vez mais confrontados, ou alternativamente fundidos com discursos de valor simbólico agregado; recursos semióticos produzidos pelo nacionalismo característico do capitalismo industrial (tais como bandeiras, linguagem, traje tradicional, personagens heroicos ou icônicos e formas de cultura) mobilizados em atividades econômicas para criar nichos de mercado voltados para turistas, ao agregar, por exemplo, valor a

9. Esses contextos deram origem a concepções de nação contrastantes: por um lado, a de nação como "indivíduo coletivo", que enfatiza a singularidade (Volk), herdeira do romantismo alemão, e, por outro, como coleção de indivíduos, do iluminismo francês (DUMONT, 1995). O contraste é aqui um recurso teórico-metodológico, pois compreender as formas de atualização de Estados-nações depende de verificação empírica. 
produtos ou mobilizados como produtos por si mesmos; e, por fim, fenômenos construídos como problemas pelos nacionalismos e mercados industriais, com foco em limites e uniformidade, como multilinguismo e variabilidade, sendo reformulados como ativos econômicos e como marcas (HELLER; DUCHÊNE, 2016, p. 143-144).

São ideologias da linguagem coexistentes que podem gerar tensões a partir de espaços conturbados de contradição entre, por exemplo, padronização e variabilidade linguística - subjetividades produzidas em termos de performances e valores identitários locais - e técnicas de gestão utilizadas para regular e medir o valor das habilidades linguísticas. No campo do turismo especificamente, conforme Heller, Jaworski e Thurlow (2014) assinalam, isso propicia que recursos multilíngues sejam empregados em uma tensão permanente entre a busca pela autenticidade das línguas e culturas locais e a mercantilização, de modo que repertórios linguísticos passam a ser definidos e organizados como uma mercadoria em termos de produção, distribuição e consumo quando comparados a outras línguas que se posicionam dentro de um mercado linguístico. Em performances midiáticas cômicas, nas quais membros de comunidades étnicas utilizam a linguagem desse grupo para produções humorísticas, conforme Jaffe (2009) analisou na Córsega, parte da tensão e do efeito dessas atuações cômicas deriva da visão dominante das línguas como códigos fixos e limitados que indiciam identidades únicas. São produções cujos performers enfatizam a maneira de o híbrido definir o público como uma comunidade, expressando um "nós", por meio do gozo compartilhado de códigos mistos. Da Silva (2015) analisa, por sua vez, performances midiáticas luso-canadenses no Canadá e afirma que elas são simultaneamente empoderadoras e degradantes, porque colocam em evidência, por um lado, usos da linguagem e seus falantes, visibilizando-os, e, por outro, a forma mimética como é realizada pode acontecer de modo bastante degradante. Isso significa que, para analisar o papel central da linguagem na economia atual, como na festa da localidade em questão, não podemos ignorar o valor atribuído às práticas de linguagem e seus vínculos com todo tipo de atividade social.

\section{2. "UMA CIDADE DE PESSOAS QUE LEVAM A CULTURA GERMÂNICA NO CORAÇÃO"}

O Município foi colonizado em 1962 por uma colonizadora que foi "Procuradora da Diocese" (LUNKES, 2005) ou da "Gleba dos Bispos" (KLAUCK, 2004), conforme nomeada por um padre que era o responsável pelo processo de assentamento e de edificação de obras de cunho pastoral. A história da Cidade está articulada à política do governo federal brasileiro que, na década de 1940, procurou "ocupar terras do oeste brasileiro", a fim de "promover o desenvolvimento e o progresso do país", ideal impulsionado e politizado pela "marcha para o Oeste" no governo de Getúlio Vargas. No Paraná, mais especificamente, houve, na década de 1920, uma grande preocupação com as fronteiras com o Paraguai e com a Argentina, locais onde havia pouquíssimos falantes de português e a moeda corrente era o peso argentino. Um acordo assinado pelo governo imperial em meados do século XVIII permitiu a navegação argentina e paraguaia por águas brasileiras, o que possibilitou à Argentina explorar a erva-mate e a madeira na região por meio das obrages ${ }^{10}$. "O acordo que havia sido selado estimulou o desenvolvimento das obrages e o monopólio do comércio e da navegação pelo rio Paraná" (PRIORI et al. 2012, p. 81).

Quando foram finalizadas as concessões, as terras "consideradas devolutas" foram recuperadas para empresas públicas ou particulares, e o processo de "colonização"11 ocorreu em duas frentes: a frente pública, pela qual o Estado se encarregava de fazer o loteamento, e a frente privada, a cargo de empresas de colonização e imobiliárias. O referido Município foi colonizado por uma das empresas privadas, a Sipal Colonizadora Ltda., do Norte do Paraná. Essas empresas privilegiaram a venda das terras em pequenas propriedades com cerca de 10 alqueires ( $24 \mathrm{ha}$ ), garantindo que cada propriedade tivesse um curso de água. Os compradores eram selecionados rigorosamente. A preferência era por gaúchos e catarinenses com ascendência alemã ou italiana. Seguindo as diretrizes dessa política, o Município foi "colonizado" por católicos da terceira ou quarta geração de imigrantes alemães vindos, em sua maioria, do noroeste

10. Os obrageros eram os empreendedores interessados em explorar produtos nativos e, para isso, contratavam mão-de-obra que não era brasileira, mas "era principalmente paraguaia de descendência [sic] indígena. Para expandirem seus lucros, estas companhias adotavam alguns artifícios, como o do monopólio e o da extrema exploração de mão-de-obra" (GREGORY, 2012, p. 46).

11. Colonização é a categoria utilizada na história oficial do Município para descrever a vinda de descendentes de imigrantes para realizar o povoamento do local. Contudo, narrada como colonização, essa história vem sendo questionada por ser um ponto de vista oficial e hegemônico, pois não leva em consideração grupos que já habitavam esses locais. Trata-se, segundo Quijano (2009, p. 73), de "uma estrutura de dominação/exploração, cujo controle da autoridade política, dos recursos de produção e do trabalho de uma população determinada, domina outra de diferente identidade [...]". Por essas razões, usamos aspas tanto para identificar o uso local quanto para suspender seu significado hegemônico. 
do Rio Grande do Sul, atraídos pela oferta de lotes de terras. Conforme consta no site oficial da Prefeitura Municipal, esses descendentes trouxeram consigo características identificadas por eles como de "cultura germânica" (expressa nas construções de casa em estilo enxaimel, nos jardins floridos e na gastronomia).

O nome da cidade foi inspirado na religiosidade católica dos moradores. No site da Prefeitura Municipal, essa denominação é algo inquestionável: "sem dúvida, os pioneiros escolheram e acertaram. Ninguém jamais pensou em mudar o nome e quem mora aqui pode dizer com orgulho: SOU DO MUNICÍPIO/DA CIDADE DE CORAÇÃO. O Município representa a nossa história".

No Município, porém, permanecem fronteiras étnicas internas e externas relacionadas à história da "colonização" e marcadas simbolicamente em termos de território ${ }^{12}$. Uma delas, identitária e simbólica, geradora de tensões, foi construída na relação com o município ao qual o local pertencia até o ano de 1982. Os moradores da sede daquele município, descendentes de imigrantes italianos, associavam os moradores locais a uma identidade de "colono alemão" em um sentido estigmatizante e depreciativo (JUNG, 2003; 2009). Ser falante do português local, com traços do alemão, era uma marca distintiva que os levava a associar a pessoa à ideia do "colono alemão", uma associação presente entre os primeiros moradores do local e entre os mais jovens. Trata-se de uma fronteira construída (ANZALDÚA, 1987) que levou moradores locais a se autoidentificarem como "colonos envergonhados" (JUNG, 2009).

A outra fronteira, interna, também está relacionada com os modos de ocupação dessas terras do Município. A historiografia oficial registra que o local foi "colonizado" por descendentes de alemães advindos do Rio Grande do Sul. No entanto, algumas comunidades rurais próximas a um dos rios que banham a região foram e receberam grupos vindos de outras regiões brasileiras, pelo sistema de posses. Como afirma Parizotto (2018, p. 60), "[...] no distrito $[\mathrm{X}]$, a grande maioria das famílias é de descendentes italianos e brasileiros. Já nas demais comunidades e distritos do município, a descendência alemã prevalece [...]."

Essas fronteiras simbólicas e identitárias penetram as experiências cotidianas da cidade. A pesquisa de Jung (2003), realizada em uma escola do distrito do Município, onde a maioria das famílias é descendente de alemães, mostrou que tais construtos identitários e simbólicos caracterizam o "colono alemão" como uma categoria social marcadamente masculina, proprietária de terra, em oposição aos habitantes da área do Município ocupada por um sistema de posses. Os primeiros se viam como proprietários legítimos porque "compraram suas terras", mas eram ameaçados na relação com os habitantes da cidade-polo microrregional. A língua alemã era, assim, um traço da identidade masculina local estigmatizada e associada à vida rural. As mulheres desse grupo procuravam apagá-la, uma vez que a vida rural era-lhes pouco atraente. Elas buscavam o letramento em português, o uso do brasileiro e o conforto da vida da cidade, almejados para a conquista de prestígio local.

A escola, por meio de um modelo de letramento associado localmente a uma identidade feminina, ratificava positivamente em sala de aula essa identidade prestigiosa na comunidade local. Os traços dessa identidade eram cossustentar os pisos conversacionais propostos pela professora, apresentar a resposta esperada, produzir a segunda parte do par adjacente inicial da sequência Iniciação-Resposta-Avaliação, apresentar voluntariamente o caderno para a correção, organizar devidamente a atividade no caderno e zelar pelo asseio corporal. As meninas e os meninos que tornavam relevantes traços de outras identidades - a masculina, a étnico-linguística alemã, a racial negra, a religiosa evangélica pentecostal ou a de repetente - viviam conflitos de identidade na escola. O menino da $1 .{ }^{a}$ série, por exemplo, era identificado como "colono alemão" pela desorganização do material escolar e pelas unhas sujas de terra, vistas como falta de asseio corporal. São construtos sociais e/ou identidades, com percurso histórico anterior, que emergiam na atuação dos alunos em sala de aula. Embora alguns meninos da $4 .^{a}$ série, que compartilhavam outros valores simbólicos, tivessem aprendido a negociar os traços dessa identidade feminina hegemônica da escola e conquistassem status de ótimos alunos, esse letramento significava uma trajetória muito mais complexa para os meninos na escola do que para as meninas.

Por fim, é importante mencionar as ressonâncias do nacionalismo no Brasil presentes no preconceito existente localmente. O nacionalismo tornou-se uma política de Estado no século XX, durante o Estado Novo. Mais

12. Essas fronteiras advêm dos conflitos das narrativas da ocupação do oeste do Paraná: "Enquanto que as visões das companhias colonizadoras e de representantes do poder político estão expressas em discursos que justificam as suas ações em prol do desenvolvimento da região, a ótica das pessoas comuns pode ser buscada na memória social da população do Oeste do Paraná. Muitas vezes, um imaginário que ainda carrega as marcas do poder e violência a que foram submetidos. Por isso, ao falarmos da colonização do Oeste do Paraná, é importante lidarmos com as múltiplas interpretações que esse tema nos fornece, por mais que a história oficial tente apagá-las" (PRIORI et al., 2012, p. 88). 
especificamente, entre 1937 e 1945, houve a "Campanha de Nacionalização", que visava promover o caldeamento de todos os alienígenas em nome de uma pretensa unidade nacional (SEYFERTH, 1997). Nessa campanha, a repressão linguística, sob o título de "nacionalização do ensino", conforme o Decreto 406, de 4 de maio de 1938, determinava uso de materiais didáticos exclusivamente em língua portuguesa; obrigatoriedade de brasileiros natos para serem professores e diretores nas escolas brasileiras; proibição da circulação de texto, revista ou jornal em língua estrangeira; proibição do ensino de língua estrangeira a menores de 14 anos; e uso obrigatório da bandeira nacional em dias festivos. Ou seja, a língua portuguesa foi o critério fundamental de nacionalização, cuja justificativa se referia ao ensino e ao fechamento das escolas que funcionavam em outras línguas de instrução, como o alemão. O decreto atingiu particularmente imigrantes alemães, italianos e japoneses, e a repressão adquiriu novos contornos em 1942, quando o Brasil participou da Segunda Guerra, enquanto os países de origem desses imigrantes estavam contra os Aliados aos quais o Brasil se filiou mais tarde.

A repressão linguística do Estado Novo, distante no tempo, permanece entre os moradores do local como uma espécie de memória coletiva não expressa, fazendo com que o alemão reapareça, com outros significados, na Deustches Fest. Talvez tenham vivenciado esse período de "campanha da nacionalização" antes de migrarem do Rio Grande do Sul para o Paraná, movimento visível na nomeação da língua portuguesa como brasileiro, a qual precisariam aprender para fazer parte da nação. Entre os moradores, há então aqueles que falam alemão e brasileiro, só falam alemão e só falam brasileiro. No contexto da festa, aparece também o alemão padrão na divulgação e durante a realização da festa - em mensagens de boas-vindas, para expressão do ânimo alegre da festa, nomeação de comidas e recreações -, que são usos para os quais consultam professores locais para garantir a correção das palavras e das frases. Trata-se aqui de uma tensão entre o alemão falado localmente e uma ideologia de língua padrão, vista como necessária para a escrita. Essa escrita é inseparável dos símbolos que caracterizam os souvenires da festa.

\section{DEUTSCHES FEST: UM GRANDE EVENTO DE MÚLTIPLAS SIGNIFICAÇÕES}

A compreensão da festa como atividade ritual por expressar uma maneira de perceber, interpretar e experimentar aquilo que se deseja identificar como "sociedade" ou um grupo social é um tema de interesse de algumas abordagens analíticas da Antropologia. Apesar de diferenças entre elas, as festas não são compreendidas como eventos pontuais e independentes, mas rituais que "falam" a respeito de um dado contexto social, vivificando-os (DURKHEIM, 1983; DUVIGNAUD, 1983). No Brasil, DaMatta (1983) estudou o dia da Pátria (7 de setembro), o Carnaval e as festas religiosas como manifestações da identidade brasileira em seus valores críticos e essenciais que se complementam de modo múltiplo ao cotidiano. O dia da Pátria é, assim, uma festa de celebração da ordem social com suas diferenças, gradações, poderes e hierarquias; o Carnaval é a festa da inversão dessa ordem; e as festas religiosas celebram valores sagrados considerados básicos para a possibilidade de restituir o significado transcendente do mundo. $\mathrm{O}$ modo como pensamos e experimentamos as festas coletivas é um dado sociológico fundamental, mas aqui será considerado, sobretudo, do ponto de vista da linguagem da festa: um evento comunicativo que engloba significados e símbolos do contexto identitário e linguístico do local.

A Deutsches Fest acontece anualmente na cidade, desde o ano de 2002, quando foi criada por um grupo de jovens locais que participavam da Junior Chamber International (JCI) Brasil, uma organização não governamental mundial composta por jovens entre 18 e 40 anos. É identificada como "uma organização de líderes" que busca "no aprimoramento individual as bases para o desenvolvimento de suas comunidades"13. Na época, jovens locais participantes dessa organização, como nossa entrevistada Ludmila, apresentaram uma proposta de realização da festa à Câmara dos Vereadores, que a aprovou. Além de uma análise de práticas de linguagem da festa, entrevistamos dois organizadores de edições diferentes da festa: Ludmila, que participou da idealização da primeira festa, funcionária pública, é filha de descendentes de alemães. Tem mais de 50 anos, nível superior de escolaridade e participa do coral da igreja católica. Raimundo, com mais de 60 anos, era o responsável pela organização da festa pela Secretaria Municipal, também filho de descendentes de imigrantes alemães, comerciante, foi vereador do Município na década de 1990 .

13. Conforme informativo do website da associação no Brasil. Na apresentação intitulada "Quem somos", no texto intitulado "Uma organização de líderes", também afirmam: "A JCI se utiliza da energia e do entusiasmo dos jovens para desenvolver seu espírito de iniciativa e liderança defendendo a liberdade de imprensa, os direitos do indivíduo, estimulando a fraternidade entre os homens e servindo a humanidade, sob a égide da liberdade e da democracia". 
A proposta inicial da festa consistia em trazer práticas de linguagem da cultura local, como o alemão falado ainda por muitos, especialmente por pessoas mais idosas, associando-as às culturas alemãs de outros períodos por meio da grafia antiga, no assim chamado estilo gótico, da bandeira alemã e suas cores, das comidas típicas, como a cuca e o salame ${ }^{14}$, e de elementos de festas comuns, como os bailes, bandinhas, e a escolha da rainha anual da festa. Segundo nos disse Ludmila, a ideia da festa foi "copiada" de outros lugares, como Blumenau e São Paulo das Missões (cidade rio-grandense de onde vieram famílias que "colonizaram" o local), mas justificada como necessidade de manter a "cultura germânica" local. Desde então, a festa passou a ser realizada anualmente, sempre uma semana após a Páscoa, com 18 edições até o ano de 2019. A identificação da cidade como a terra da Deutsches fest levou a administração municipal a reivindicar exclusividade local para a atração como um contraponto a outros atrativos turísticos muito próximos: as Cataratas do Iguaçu e a Usina de Itaipu, em Foz do Iguaçu, restaurantes com comidas típicas, em Puerto Iguazú, na Argentina, e o turismo de compras em Ciudad del Este, no Paraguai.

Além da Deutsches fest, acontecem mais cinco festas localmente: o Café Colonial, a Festa dos Navegantes (alusiva à emancipação do Município), o Baile do Colono e do Motorista (evento para evidenciar a importância das duas categorias para o desenvolvimento do Município), a Pesca da Corvina e o Baile de Escolha da Miss. Todavia, a Deutsches Fest é a festa promovida como atrativo turístico único, cujo objetivo, conforme veiculado no site da Prefeitura, é a "preservação da cultura germânica" e, para isso, possui atrações como desfiles alegóricos, bailes, jogos recreativos, apresentações artísticas, concurso de chopp em metro e comidas "tipicamente germânicas".

O evento reúne grande número de pessoas de toda a região e do estado, que prestigiam, durante os três dias, a "cultura germânica". Na sexta-feira à noite, ocorre a abertura oficial com desfile de carros alegóricos, transportando as rainhas, princesas e um casal de idosos escolhidos a cada ano, os quais recebem os nomes "típicos" de Fritz e Frida, as autoridades locais (prefeito, vice-prefeito, presidente da câmara de vereadores), além dos carros alegóricos de grupos que se inscreveram no evento, como será detalhado na seção seguinte. Em seguida, há o jantar típico, no qual é servido Eisbein (joelho de porco), marreco recheado, chucrute, salsichão, repolho roxo, purê de batata, além de lanches típicos, "como porções de cuca e salame, cachorrão, batata recheada, hambúrguer típico, entre outros ${ }^{15 "}$. Os pratos típicos são servidos também no sábado à noite e no almoço de domingo. O concurso da rainha é feito nessa primeira noite, além de haver apresentações culturais, o concurso do chopp em metro e baile. No sábado e no domingo, à noite, também se realizam bailes animados por bandas geralmente famosas na região Sul do país. Durante todo o domingo, há jogos recreativos. Além dos moradores, há um grande número de participantes de fora, a maioria residente em cidades próximas, embora haja visitantes de outros estados. Muitos visitantes ficam durante todo o tempo da festa reunidos. Segundo Raimundo, todos os hotéis da cidade e das cidades vizinhas ficam totalmente ocupados, e alguns moradores alugam as próprias casas. Todas essas manifestações são também modos de apropriação e de participação transformadas em consumo de bens simbólicos alusivos à "cultura germânica". Na seção a seguir, descrevemos e analisamos práticas de linguagem como recursos comunicativos que visam autenticar os bens culturais germânicos a serem comprados e consumidos na festa.

\section{PRÁtICAS DE LINGUAGEM: “COM CERTEZA, A LINGUAGEM VENDE"}

A Deutsches Fest é um evento festivo público e coletivo que celebra o pertencimento a um grupo identitário - descendentes de imigrantes alemães contrastados com a nacionalidade brasileira - espacial e temporal, e procura anunciar e vender produtos alusivos a esse pertencimento e a esse local. A festa envolve, portanto, práticas de linguagem que expressam significados simbólicos e econômicos, como o deslocamento e a trajetória migratória dos descendentes de alemães do Rio Grande do Sul para o oeste do Paraná; a identificação que singulariza a cidade em contraposição a essa região do oeste paranaense e ao País; e a passagem do status desvalorizado de "colono" para o orgulho de morador da cidade. Vejamos como emerge a busca de autenticação dessas práticas de linguagem relacionadas aos preparativos da festa e em práticas da festa.

\footnotetext{
14.Embora os termos de referência a esse prato típico em muitas comunidades de ascendência alemã sejam "cuca e linguiça", na Deutsches Fest, ele é anunciado e vendido como "cuca e salame". Desconhecemos a origem desse uso local, mas há uma diferença localmente entre linguiça ou linguicinha, assada em churrascos, e salame defumado pronto para consumo.

15.Conforme informação no website da festa, "A origem dos pratos típicos é essencialmente germânica, com o gostinho do tempero local."
} 


\subsection{Preparativos da festa: "Todos os caminhos levam à Deutsches Fest"}

Um panfleto de divulgação da festa, mais especificamente da 15. a edição, ocorrida em 2016, iconiza a forma de barril onde se vê a figura de um homem e uma mulher com cabelos louros, vestidos "tipicamente" como alemães, dançando e brindando. Ali se lê o seguinte enunciado, entrelaçado à figura na parte superior: "O Município/A Cidade: terra da Deutsches Fest - Festa alemã". É importante observar que a escrita de Deutsches Fest mimetiza a antiga grafia gótica do alemão.

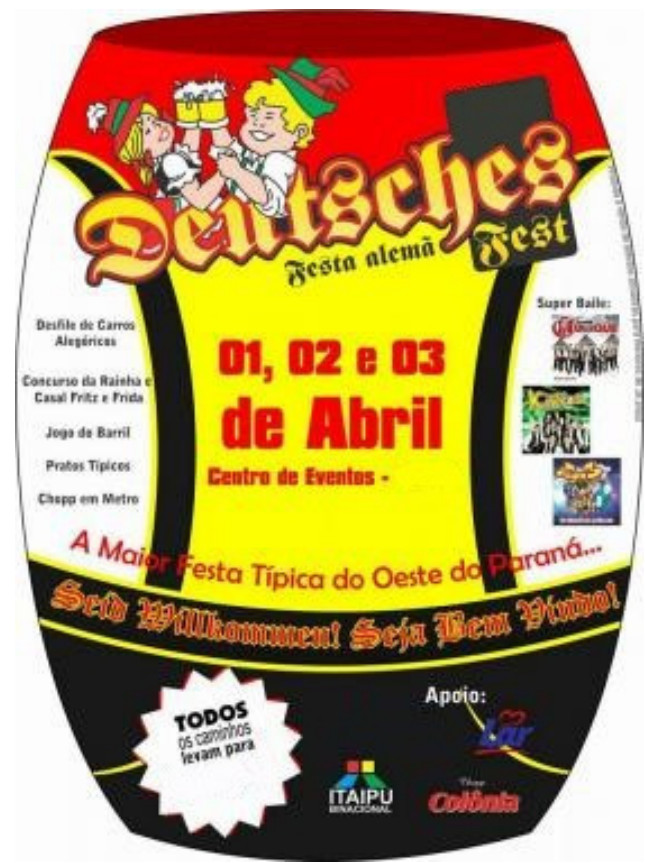

Figura 1. Panfleto de divulgação da $15 .^{a}$ Deutsches Fest

Fonte: Site da festa

No centro do barril, com fundo amarelo, constam a data e o local e, logo abaixo, a escrita "A maior Festa Típica do Oeste do Paraná...". Aqui temos um enunciado que busca atribuir autenticidade à festividade, ou seja, não se trata de qualquer uma, mas da maior festa "típica" [alemã] que acontece no Oeste do Paraná. Logo abaixo, há uma faixa no barril com a inscrição "Seid Willkommen! Seja Bem Vindo!". Nesse mesmo espaço/faixa, repete-se o uso de estilização de grafia gótica. Na parte inferior do barril, com fundo preto, em uma figura em formato de balão com fundo branco, lê-se: "Todos os caminhos levam para o Município". À direita desse balão, estão os logotipos dos órgãos apoiadores: Prefeitura, Itaipu Binacional ${ }^{16}$, Lar Cooperativa ${ }^{17}$ e Chopp Colônia ${ }^{18}$. As duas últimas são empresas da região que têm uma grande produção para o mercado nacional e internacional, e a Itaipu é uma das maiores geradoras de energia do mundo.

Nas laterais do barril, com fundo branco, estão descritas as atrações da festa: à esquerda, Desfile de carros alegóricos, Concurso da Rainha e Casal Fritz e Frida, Jogo do Barril, Pratos Típicos, Chopp em Metro; e, à direita, Super Baile, com cartazes de propagandas informando quais conjuntos musicais tocarão nos três dias de baile.

O panfleto de divulgação traz recursos da língua alemã padrão. A escrita em alemão foi comum no Brasil no período entre 1890 e 1940, quando inúmeros jornais foram editados em alemão e impressos com tipos góticos. ${ }^{19}$ Além desse recurso, as cores da bandeira da Alemanha, a figura e as descrições em português são todas utilizadas para

16. "A Itaipu Binacional há alguns anos tornou-se um atrativo turístico."

17. "A Lar Cooperativa é uma cooperativa agroindustrial criada em 1964 por 55 pequenos agricultores do RS e SC que se uniram na antiga Gleba dos Bispos, onde atualmente fica o Município. Segundo informação oficial [...] em 2020, a Lar Cooperativa cresceu 55,14\% e faturou R\$10,78 bilhões".

18. O Chopp Colônia é produzido pela Indústria Nacional de Bebidas (INAB), em um munícipio próximo, onde atua há mais de 20 anos. Produz algumas cervejas, como Cerveja Colônia, Stell, Haker, Doblee e Dankel, para o mercado externo, mais especificamente para o Paraguai, Bolívia, Uruguai, Colômbia, Costa Rica e Argentina.

19. De acordo com Straub (2003, p. 257), "O grande número de veículos editados em alemão e impressos com tipografia gótica [em Curitiba] se deveu sobretudo à simbologia do elemento tipográfico para os germânicos, que, além do elemento que de certa forma os unificava, também os fazia se sentirem mais próximos de sua terra natal bem como de seus costumes." 
convidar pessoas ou turistas como meios de conferir autenticação à maior festa típica [alemã] do Oeste do Paraná. Nessa prática, a linguagem alemã escrita expressa o nome da festa e as boas-vindas, e o português escrito anuncia suas atrações. O estilo da grafia gótica associado à língua alemã padrão é sobreposto ao português na tradução do nome e da mensagem de boas-vindas, evidenciando uma intercessão entre línguas-padrão, delimitadas, e, nesse caso, a grafia gótica como forma de imprimir ainda mais autenticidade.

Há ainda outras práticas de linguagem relacionadas com uma ampla divulgação de caráter local e regional. São anúncios veiculados na rádio local e da região, em programas de tevê - RPC TV, concessionária da Grupo Globo -, e em postagens no Facebook e no Instagram. Além disso, um dos funcionários da prefeitura local, Liu, que é descendente de imigrantes alemães, se tornou uma espécie de promoter da festa, participando de programas de tevê, por exemplo, com rainhas da festa do ano anterior e membros da comissão organizadora do evento. Ele também grava vídeos que circulam na internet convidando para a festa.

No trecho a seguir transcrito, Liu estiliza performaticamente o português local para autenticar a festa, ao mencionar os produtos encontrados pelos participantes na cidade e ao valorizar o envolvimento e o orgulho local nos preparativos para sua realização:

Seid Willkommen ao Município/à Cidade viu, é sejam bem-vindos à Cidade, terra da Deutsches Fest. O Liu veio pra avenida hoje pra ver um pouco da decoração, esse clima de Deutsch e falar um pouco com o pessoal envolvido né, que põe a mão na massa, que dá esse clima gostoso pra cidade [...] viu! [...] A gente vai mostrar mais um pouco do Stadt. [...] Esse envolvimento que é bonito. (Fonte: Vídeo Deutsches Fest - Liu, disponível no canal do Youtube)

A avenida central, única do Município, é o espaço onde se faz a decoração, e Liu destaca o envolvimento dos comerciantes e do poder público municipal nessa ação (embora as representantes do Conselho da Mulher sejam as responsáveis por enfeitar e preparar a cidade para entrar no clima da Deutsches Fest). A fala de Liu é, em certa medida, performatizada, pois enuncia um português local de maneira bem acentuada, pronunciando, com bastante ênfase, sonoras como surdas, ou seja, /p/, /t/ e / k/; consoantes oclusivas, alveolares, surdas são alternadas livremente com [b], [d] e [g]. Essas últimas, nesse contexto, são usadas também como surdas. O /1/ é usado como fricativa, palatal, surda, e o /x/ como consoante fricativa, velar, surda e está em distribuição complementar com [ç] e [h]. Assim "Sejam bem-vindos ao Município/à Cidade, terra da Deutsches Fest" é expresso por Liu mais ou menos da seguinte forma: [Sexam pem findos à Cidade, tera da Deutsch Fest].

A performance midiática de Liu, ao divulgar o evento na televisão e em propagandas, usando trajes típicos e empregando o português local, contribui para a construção de uma identidade alemã local ao convidar orgulhosamente para a festa. Essa prática leva a uma identificação do público, conferindo-lhe autoridade estética e cultural (JAFFE, 2009), e altera alguns preconceitos linguísticos dos falantes de alemão na cidade e na região, agora mais distanciados da imagem do "colono envergonhado".

As práticas performatizadas por Liu reafirmam e revivem tradições que, articuladas aos interesses comerciais na criação de um mercado turístico local, significam afirmação do crescente orgulho de ser do local, identificação indissociável de ser pertencente à "cultura germânica". Em contraposição, a mesma performance foi utilizada para um efeito inverso: um comediante da mesma região, morador de uma cidade próxima, conseguiu fama nacional devido a suas performances humorísticas como falante de alemão por meio de atuações pejorativas, degradantes (DA SILVA, 2015), associadas ao "colono alemão local" daquele município.

As práticas de linguagem estão relacionadas de outros modos também com a decoração da avenida. Na entrada da Cidade, para quem vem da cidade polo microrregional, há uma faixa, no centro da avenida, indicando Deutsches Fest e, logo acima dela, estendida de forma vertical, a bandeira da Alemanha. Seguindo na avenida, cerca de 50 metros adiante, há outra faixa onde está escrito "Wilkommen", também acompanhada da bandeira da Alemanha sobre esses dizeres. Na mesma avenida, a maioria das lojas comerciais adorna os pilares da frente do estabelecimento com as cores da bandeira da Alemanha. Elas enfeitam as vitrines com flores vermelhas e amarelas, canecos de chopp e escritos como: "Ein prost" ("um brinde") e "Hier wir trinken" ("Aqui nós bebemos"). Outra prática interessante é a montagem de cenários para fotos em alguns pontos da cidade, geralmente em frente a lojas comerciais. É colocada, ao fundo, uma espécie de cortina nas cores da bandeira alemã e um tablado de madeira com dois cepos de madeira para assentar, enfeitados com plantas dos dois lados, simulando duas palmeiras. Trata-se de uma espécie de porta com cortinas, montada para moradores locais e turistas registrarem o momento por meio de fotos, práticas que utilizam 
símbolos denotadores da origem étnica dos moradores, representada pela bandeira da Alemanha e suas cores, a fim de "autenticar" a participação nessa festa singular.

Compõem ainda a decoração, carroças, charretes, bicicletas, rodas de carro e de bicicleta, colocadas no centro da avenida principal e em outros locais. Tais objetos são tanto símbolo do cotidiano da vida no campo quanto remetem a um passado idílico/pitoresco, à ideia de um campo atrasado, mas puro, em contraste com a cidade vibrante, mas corrompida, que inclui a história da fundação da cidade (WILLIAMS, 1989). Nessas carroças, veem-se, além de flores, tecidos com as cores da bandeira da Alemanha, barris de chopp e de leite, mensagens escritas em alemão, algumas no padrão, como "Gute Leute" e "Hier vir trinken", e outras no alemão local, como "Net stressiat", e trechos de letras de música popular (bandinhas) "Zig, Zag, Oi, Oi". Essas práticas evidenciam a linguagem também como um dos souvenires principais da festa. Os elementos decorativos sintetizam o deslocamento ao indicar o modo como moradores do Município utilizaram carroças para levar objetos de mobília, ao veicular os discursos da trajetória migratória dos descendentes de alemães do Rio Grande do Sul para o Oeste do Paraná, ao expressar a origem étnica e o multilinguismo local. Tais práticas de linguagem, como se vê, buscam autenticar a "cultura germânica".

\subsection{Práticas da festa: "A maior festa típica do Oeste do Paraná..."}

As carroças, mencionadas acima, compõem o desfile de carros alegóricos na abertura da festa, transportando, por exemplo, crianças, barris de chopp e outros elementos dos grupos organizados em blocos. Os carros alegóricos realizam um cortejo pela avenida na abertura da festa e, para fazer isso, precisam estar inscritos, conforme regulamento da Prefeitura. Alguns distribuem chopp para as pessoas que assistem ao desfile. O tema do desfile de 2019, por exemplo, foi "Herança cultural" e tinha como objetivo "mobilizar os grupos e entidades para participação efetiva no desfile valorizando a cultura alemã". A mobilização de todas as práticas de linguagem que reúne o que, do ponto de vista da administração municipal, é "cultura germânica" é feita pela regulação dos meios expressivos para singularizar a festa e está claramente explicitada nos requisitos exigidos no regulamento de 2019 para participação: pertencer a grupos folclóricos e entidades sociais, recreativas, culturais e esportivas, clubes de serviço, entidades comerciais e industriais etc., número limitado de participantes, uso de trajes típicos e carros alegóricos "desde que veiculem música típica alemã".

O desfile, assim como a decoração da cidade, procura engajar as pessoas com a festa. Nele, há uma articulação de elementos da tradição e da cultura local para a festa. Os "trajes típicos alemães" usados para o desfile pelos blocos foram inspirados, segundo Ludmila, em vestimentas de antigos grupos folclóricos da cidade. Hoje há apenas um grupo de dança que se apresenta em festivais turísticos e folclóricos, atividades comuns no Paraná. Todos os participantes de blocos usam trajes típicos, "germânico, como se diz", embora "nem na Alemanha saberão dizer de onde surgiu", segundo Ludmila. Esses trajes são confeccionados e comercializados localmente. A Lederhosen são calças feitas de couro, que podem ser curtas ou na altura do joelho, usadas com ou sem suspensório, camisas, algumas dessas nas cores da bandeira alemã ou verde, sapato com meia branca até o joelho e chapéu, para o traje masculino. O traje feminino é composto por vestido ou saia com renda, blusa, sapato preto e meia branca também até o joelho. As mulheres, geralmente, enfeitam os cabelos com flores ou com tiara de flores. A confecção desses trajes se orienta por um dos requisitos para o desfile de carros alegóricos, conforme parágrafo 7 do referido regulamento:

Para o desfile, cada grupo deverá apresentar no mínimo 10 casais vestidos com trajes típicos sendo: calça com suspensório, camiseta e chapéu para homens, e vestido, ou saia, blusa, avental e tiara de flores para as mulheres. Os demais integrantes poderão trajar camisetas alusivas à festa com chapéu, para os homens, e tiara de flores, para as mulheres, de forma a criar uniformidade, buscando harmonia e beleza do conjunto. (Regulamento do Concurso dos Carros Alegóricos da 18. ${ }^{a}$ Deutsches Fest - 2019)

As músicas ouvidas em toda a cidade nas semanas antecedentes à festa, por meio da instalação de um sistema de som na avenida da cidade, são executadas por bandinhas, algumas gravadas por conjuntos musicais que tocarão em um dos bailes das três noites. As letras são em português, com alguma variação em hunsrückisch. São as mesmas músicas tocadas, geralmente, nos bailes realizados nas comunidades rurais e por associações da cidade durante todo o ano. O estilo musical é associado, no Sul do Brasil, à cultura alemã e utiliza basicamente instrumentos como teclados e saxofone. De acordo com Stamboroski Jr. (2011), é um gênero híbrido composto por marcas de estilos trazidos da Europa, como polca, marcha, valsa, mazurca e xote, misturado por bandas ou propostas individuais, com rock ou, mais atualmente, com remix funk carioca, por exemplo. 
As práticas descritas até aqui compõem a festa, enfatizam um particularismo local (descendentes de alemães) que retoma a história de migração do noroeste do Rio Grande do Sul para o Oeste de Santa Catarina e do Paraná e que caracteriza a "colonização" do local. Os falantes de alemão são, atualmente, os moradores mais antigos, cujo espaço e representação estão garantidos na performance de Fritz e Frida. No baile, realizado no sábado à tarde, a geração mais nova participa com orgulho da "cultura germânica". Contudo "agora a população é muito misturada, porque pessoas vêm trabalhar nos frigoríficos e escolhem a Cidade pelo custo de vida baixo", como afirmou Raimundo, indicando que nem todos os "moradores locais" participam do mesmo modo da festa e da "cultura germânica". Isso também ocorre na identificação de si que singulariza a Cidade em contraposição com a fronteira étnica da região colonizada pelo sistema de posses no Município, não visível na festa.

A festa é anunciada como a mais típica do Oeste do Paraná e, para Ludmila, "com certeza, a linguagem vende", como também os outros recursos linguísticos mobilizados para compor as práticas descritas. Para os moradores locais, essas práticas articulam, de modo indissolúvel, os recursos linguísticos com elementos culturais e de tradição vendidos na festa.

Um dos mais claros indícios da transformação da festa em uma propriedade e marca da Cidade foi a certificação, em 2018, dada pelo Instituto Nacional Industrial, "de garantia de propriedade e uso exclusivo do Município do nome Deutsches Fest como uma marca, uma vitória muito grande", conforme Raimundo. A marca transformou-se, por iniciativa de funcionários da Prefeitura Municipal, em um logotipo, como mostra a Figura abaixo, formado pela sobreposição da palavra Deutsches Fest, colocada em primeiro plano, à figura de um casal usando roupas típicas, brindando com duas canecas de chopp. Com a mesma escrita em caracteres da grafia gótica da língua alemã, a figura está impressa em papéis e envelopes timbrados, incorporada como marca distintiva dos documentos oficiais da Prefeitura local e, desde então, usada cotidiana e independentemente do momento festivo.

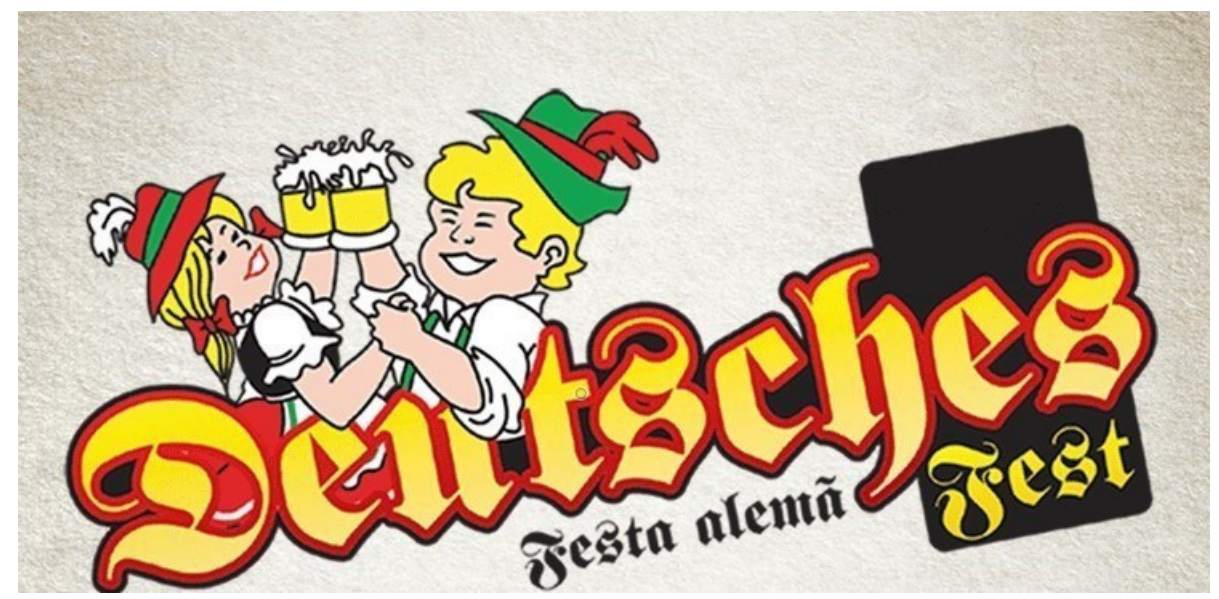

Figura 2. Logotipo presente nos documentos oficiais

Fonte: Cópia de documento oficial

Transformar a expressão Deutsches Fest em marca é transformar a linguagem em termos comerciais (econômicos) e oficiais (públicos) para circulação da expressão nos documentos oficiais da Prefeitura e registrada como direito de posse legal. Isso significa seu uso para a produção de mercadorias como processos e bens de serviços que abrangem organização, divulgação (rádio, TV, internet etc.), produção e circulação de serviços de entretenimento e divertimento, que são objetivados no evento festivo como um produto turístico lucrativo. No momento em que fizemos a entrevista, estava em processo um trâmite para registrar a festa no Cadastro Nacional da Pessoa Jurídica, dotada de entidade própria. O nome, ao ser mobilizado como mercadoria, é um meio de estabelecer distintividade, garante uma reserva de mercado e de proteção comercial exclusiva, e abre possibilidades para multiplicação e atribuição de valor a muitas outras práticas de linguagem tornadas mercadorias.

A ideia da festa e de todos os elementos a compõem como cópia, ou mesmo cópia de outras cópias, pois os entrevistados não sabiam ao certo de onde surgiram, e resulta em um conjunto de práticas linguísticas reguladas por regras tácitas, aceitas, e que se tornaram oficiais e comerciais. Trata-se de uma "tradição inventada" que, por meio da repetição, implica uma continuidade em relação ao passado. 
Hoje, de acordo com Ludmila e Raimundo, o evento possibilitou aos jovens se sentirem orgulhosos dos "trajes típicos" e do vínculo deles com a ascendência alemã. Segundo Ludmila, a Deutsches fest fez com que os moradores se interessassem pela Cidade e tentassem fazer o melhor para tornar a festa mais bonita a cada ano. Ela ressalta ainda que as pessoas gostam de dizer que são daqui agora, vista como uma cidade organizada e limpa.

\section{DEUTSCHES FEST: A REVERSÃO DA VERGONHA PARA ORGULHO}

Ter analisado a Deutsches Fest à luz dos debates recentes sobre mercantilização da linguagem fez com que observássemos um caminho complementar, em parte inverso ao tematizado por Heller $(2003$; 2010) e Heller e Duchêne $(2012 ; 2016)$, de lucro para orgulho. No caso, as práticas de mercantilização da linguagem apontam não somente para lucro, mas para uma reversão da relação dessas práticas com uma identidade pouco valorizada para outra mais valorizada simbolicamente: o que remetia ao "colono envergonhado" passa para o "orgulho de ser do local". Onde não havia orgulho local da herança de colono, os movimentos contemporâneos de mercantilização e a globalização propiciaram uma (re)invenção de um germanismo histórico difuso em associação com a ideia de uma Alemanha prestigiosa. O fato de terem sido comercializadas práticas de linguagem na festa fez com que as pessoas se tornassem orgulhosas de serem do local. Antes, o modo de falar brasileiro e o modo de ser de moradores locais eram estigmatizados pelos moradores do município vizinho, de tal modo que se sentiam envergonhados nessas interações e na identificação de si como "colono".

A Deutsches Fest, portanto, se tornou um atrativo turístico de grande importância econômica e comercial, instituiu-se como um evento festivo público e coletivo dos moradores da Cidade e gerou, como um efeito inesperado, a celebração do orgulho do pertencimento a um grupo identitário - descendentes de alemães e "colonizadores" do local. No Município, "cultura germânica" está associada à ideia de uma "cultura alemã" buscada para a festa, cujos elementos característicos, como vestimenta, comidas e bebidas típicas, músicas etc., foram introduzidos por meio de "cópias" de outros lugares.

Como um evento comunicativo, a festa veicula também a história do deslocamento migratório dos descendentes de alemães do Rio Grande do Sul para o Oeste do Paraná, identificação que singulariza a Cidade em contraposição à região e ao País. A história da migração desses descendentes de imigrantes de fala alemã, que se deu entre a repressão do Estado Novo às línguas faladas pelos descendentes de imigrantes no Brasil e o incentivo à "colonização", parece estar no entendimento comum dos moradores que associam língua a nação, falam alemão e brasileiro, e na sobreposição entre o local/regional e o nacional. Por um lado, a língua alemã (cotidiana e formal/erudita) é uma singularidade associada a um indivíduo coletivo, cuja identidade alemã de origem é comemorada na Deutsches Fest e, por outro, o brasileiro que identifica o pertencimento à nação brasileira como uma coleção de indivíduos, em termos da cidadania nacional.

A festa é igualmente uma comemoração ritual que permite fazer a mediação entre passado e presente, entre o espaço local e o nacional, revigorando sentimentos que unificam moradores em um grupo singular. No tempo festivo, eles se sentem parte de um mundo em grande parte imaginado (ANDERSON, 2008), expresso nos símbolos que são identificados com a Alemanha, mesmo sem saberem ao certo a origem de alguns deles. O sentimento de pertencimento é fortalecido por elementos presentes em todas as festas: músicas, bebidas, comidas específicas, comportamentos ritualizados, danças etc. e ratificado pelos visitantes. Como em nenhum momento se questiona a autenticidade da festa como expressão da cultura alemã, há uma convergência entre busca de autenticação e mercantilização, objetivadas na reivindicação de obtenção da marca registrada da festa para fins comerciais e jurídicos pela Prefeitura local. A convergência entre autenticação e mercantilização que encontramos pode estar vinculada à estratégia metodológica por nós adotada, centrada nos meios de divulgação pública, nos documentos oficiais, nas entrevistas com responsáveis e idealizadores da festa e em nossas observações etnográficas não estruturadas. Conversando com moradores participantes e não participantes da festa e com turistas vindos de outros lugares, provavelmente encontraríamos outras relações.

O conjunto de elementos manifestos na festa, mobilizados simbólica e economicamente pela linguagem, foram impulsionados pelo contexto local do capitalismo tardio e, desse modo, instrumentalizados para a produção de um mercado turístico que alia o consumo das viagens ao consumo de "bens culturais" singulares. Esses "bens culturais", comercializados, são materializados em práticas e produtos que buscam autenticar a constituição identitária teuto- 
brasileira no Município. A convergência entre autenticação e mercantilização possibilitou que o alemão e o brasileiro, expressões linguísticas estigmatizadas do colono local, se tornassem celebrados na Deustches Fest.

\section{REFERÊNCIAS}

ALTENHOFEN, C. V.; MORELLO, R. (Orgs.) (2018). Hunsrïckisch: Inventário de uma Língua do Brasil. Florianópolis: Editora Garapuvu.

ANDERSON, B. (2008[1983]). Imagined communities: Reflections on the origin and spread of nationalism. Londres: Verso. [Tradução brasileira: Anderson, B. Comunidades imaginadas. São Paulo: Companhia das Letras.]

ANZALDÚA, G. (2009) Como domar uma língua selvagem. Tradução de Pinto, J. P.; Santos, K. C.; Veras, V. Cadernos de Letras da UFF - Dossiê: Difusão da língua portuguesa, n. 39, p. 297-309.

BOURDIEU, P. (1982). A economia das trocas linguísticas: o que falar quer dizer. 2. Ed. São Paulo: Editora da Universidade de São Paulo.

BOURDIEU, P. (2017). A Distinção: crítica social do julgamento. São Paulo: Edusp; Porto Alegre, RS.

BOURDIEU, P. (2007). Escritos da Educação. Petrópolis, RJ: Vozes.

DAMATTA, R. (1983). Carnavais, malandros e heróis: para uma sociologia do dilema brasileiro. 3 ed. Rio de Janeiro, Zahar editores.

DA SILVA, E. (2015). Humor, (re)positioning ethnolinguistic ideologies: "You tink is funny?". Language in Society, v.44, n.2, p.187-212.

DUMONT, L. (1995). O individualismo: uma perspectiva da ideologia moderna. Rio de Janeiro: Rocco.

DURKHEIM, E. (1983). As formas elementares da vida religiosa. Os Pensadores. 2 ed. São Paulo: Abril Cultural.

DUVIGNAUD, J. (1983). Festas e civilizaçẽes. Fortaleza, Tempo Brasileiro.

FIORIN, J. L.; PETTER, M. (2008). Prefácio. In África no Brasil: a formação da língua portuguesa. São Paulo, Contexto, p. 7-11.

GELLNER, E. (1993). Nações e nacionalismo. Lisboa: Gradiva.

GREGORY, V. (2012). Obrages nos sertões do Paraná: exploração, trabalho e fronteiras. Ideação, 14, 1, p. 43-65.

HELLER, M.; McELHINNY, B. (2017). Language, capitalism, colonialism: toward a critical history. Toronto: University of Toronto Press.

HELLER, M.; DUCHÊNE, A. (2016). Treating language as an economic resource: Discourse, data and debate. In: COUPLAND, N. (Ed.). Sociolinguistics: Theoretical Debates. Cambridge: Cambridge University Press, p. 139-156.

HELLER, M.; DUCHÊNE, A. (2012). Pride and profit: Changing discourses of language, capital and nation-state. In: DUCHÊNE, Alexandre; HELLER, Monica (Eds.). Language in late capitalism: pride and profit. London: Routledge, p. 1-21.

HELLER, M. (2011). Paths to Post-Nationalism: a critical ethnography of language and identity. New York: Oxford University Press.

HELLER, M. (2010). The Commodification of Language. Annual Review of Antbropology, v. 39, n. 1, p. 101-114. Disponível em: $<$ http://www.annualreviews.org/doi/10.1146/annurev.anthro.012809.104951 >. Acesso em: 05 jul. 2018.

HELLER, M. (2003). Globalization, the new economy, and the commodification of language and identity. Journal of Sociolinguistics, v. 7 , n. 4 , p. $473-492$.

HOBSBAWM, E. J. (1990). Nações e nacionalismo desde 1780. Rio de Janeiro: Paz e Terra. 
JAFFE, A. (2009). Comic performance and the articulation of hybrid identity. Pragmatics, 10(1), 39-59.

JUNG, N. M. (2009). A (re)produção de identidades sociais na comunidade e na escola. Ponta Grossa/PR: Editora UEPG.

JUNG, N. M. (2003). Identidades sociais na escola: gênero, etnicidade, língua e as práticas de letramento em uma comunidade rural multilíngue. Tese (Doutorado em Letras). Programa de Pós-Graduação em Letras. Universidade Federal do Rio Grande do Sul.

KLAUCK, S. (2004). Gleba dos Bispos. Colonização no Oeste do Paraná - uma experiência católica de ação social. Porto Alegre, RS: EST Edições.

LUNKES, G. (2005). O Município/A Cidade tem muito futuro neste passado. Marechal Cândido Rondon, PR: Germânica.

OLIVEN, R. G.; GARCEZ, P. de M. (2020). "A mudança social se desenrola conflituosamente no terreno da linguagem": entrevista com Monica Heller (Professora da University of Toronto). Horiz. antropol., Porto Alegre, v. 26, n. 57, p. 315-359.

PARIZOTTO. R. (2018) MEMÓRIAS PARA EDUCAÇÃO DO MUNÍCIPE: histórias do Município por entre memórias escritas e memórias vividas. Dissertação de Mestrado em Educação. Universidade Estadual do Oeste do Paraná UNIOESTE, Cascavel.

PRIORI, A. et al. (2012). História do Paraná: séculos XIX e XX [online]. Maringá: Eduem. In: A história do Oeste Paranaense. p. $75-89$.

QUIJANO, A. (2009). Colonialidade do poder e classificação social. In: SANTOS, B. S.; MENESES, M. P. (Orgs.) Epistemologias do Sul. Coimbra: Edições Almedina.

SEYFERTH, G. (1997). A assimilação dos imigrantes como questão nacional, MANA 3(1): 95-131.

SILVA, R. C. M. (2013). Vidas, Nações e Estados se fazendo nas fronteiras entre Brasil, Paraguai, Argentina. Ideação (Unioeste. Impresso), v. 15, p. 10-32.

SILVA, R. C. M. (2020) Como Experimentamos e Entendemos, do Lado Brasileiro, as Fronteiras com a Argentina e com o Paraguai / How We Experience and Understand the Borders with Argentina and Paraguay from the Brazilian Side. Espaço aberto, PPGG - UFRJ, v. 10, p. 83-98.

STAMBOROSKI JR, A. A. (2011). Música Popular Germânica no Sul do Brasil: um panorama histórico da "bandinha" ao "pop do sul". São Paulo: Funarte. Ministério da Cultura.

STRAUB, E. (2003). A tipografia no meios editoriais de Curitiba. Dissertação de Mestrado em Engenharia de Produção. Universidade Federal de Santa Catarina, UFSC, Santa Catarina.

WILLIAMS, Raymond. (1898). O Campo e a Cidade na bistória e na literatura. Trad. por Paulo Henrique de Britto. São Paulo: Cia das Letras.

\section{REFERÊNCIAS DO CORPUS}

CARTAZES. (2019) Disponível em: https://www.deutschesfest.com.br/galerias/cartazes. Acesso em fev. 2021.

COMPROMETIMENTO COM A EXCELÊNCIA. Disponível em: http://www.inab.com.br/ Acesso em 3 abr. 2021.

Concurso da Rainha na 18. Deutsches Fest tem 08 candidatas. (2019) Disponível em: https://www.deutschesfest.com.br/noticias/ concurso-da-rainha-na-18a-deutsches-fest-tem-08-candidatas Acesso em: 25 fev. 2020.

Deutsches Fest - Liu. Disponível em: https://www.youtube.com/watch?v=52DvP6_eoZQ. Acesso em out. 2019. 
ITAIPU BINACIONAL. Turismo em Itaipu. (2021) Disponível em: < https://www.itaipu.gov.br/turismo-itaipu > . Acesso em 22 fev. 2021.

JCI BRASIL. Quem somos. Disponível em: https://www.jci.org.br/?page_id=2429. Acesso em: 22 fev. 2021.

LAR COOPERATIVA. Nossa História. Disponível em:<https://www.lar.ind.br/institucional/ > . Acesso em 22 fev. 2021.

PRATOS TÍPICOS. Disponível em: https://www.deutschesfest.com.br/pratos-tipicos. Acesso em: 22 fev. 2021.

PREFEITURA DO MUNICÍPIO/DA CIDADE. O Município. Disponível em: https://www.missal.pr.gov.br/municipio/historia. Acesso em: 22 fev. 2021.

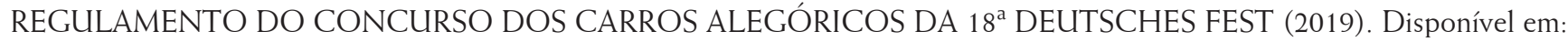
https://www.deutschesfest.com.br/noticias/regulamento-do-concurso-dos-carros-alegoricos. Acesso em: 22 FEV. 2021.

Recebido: 2/3/2021

Aceito: 14/6/2021

Publicado: XX/6/2021 